\title{
Regime de chuvas e saúde infantil no estado do Ceará: evidências para os municípios em anos censitários (1991-2010)
}

Rainfall regime and child health in the Ceará state: evidence for municipalities in census years (1991-2010)

\begin{abstract}
The current study aims to investigate the impact of rainfall regime of the municipalities of the Ceará state on child health, proxied by the child mortality rate (CMR), in census years (1991, 2000 and 2010). The regressions show a negative relationship between CMR and rainfall fluctuations, in which the exposure to infectious diseases arises as the main mechanism effect. It is also observed that CMR is particularly responsive to the occurrence of episodes of severe/extreme droughts. This result is particularly worrisome, once the climate change predictions indicate an increase in the duration and intensification of droughts in the Northeast region of Brazil. Estimates based on such projections, suggest that the loss of human capital in childhood due to the future drops in municipal rainfall level can reach $1,5 \%$ of the state GDP until the end of the $21^{\text {st }}$ century.
\end{abstract}

\section{Keywords}

rainfall regime, child health, Ceará, Brazil.

JEL Codes I15, O54.
Victor Hugo de Oliveira (1)

Cleyber Nascimento de Medeiros (2)

(1) Instituto de Pesquisa e Estratégia Econômica do Ceará

(2) Instituto de Pesquisa e Estratégia Econômica do Ceará

\section{Resumo}

O presente estudo busca investigar o impacto do regime de chuvas dos municípios do estado do Ceará sobre a saúde infantil, representada pela taxa de mortalidade de crianças menores de 5 anos (TMC), em anos censitários (1991, 2000 e 2010). As regressões indicam uma relação negativa entre a TMC e a precipitação municipal, na qual a exposição às doenças infecciosas surge como o principal mecanismo de efeito. Observa-se também que a TMC é particularmente sensivel à ocorrência de episódios de secas severas/extremas. Esse resultado é particularmente preocupante, uma vez que as previsões de mudanças climáticas indicam aumento na duração e intensificação das secas na região Nordeste do Brasil. Estimativas baseadas em tais projeções sugerem que a perda de capital humano na infância devido às futuras quedas no nivel de precipitação municipal pode atingir $1,5 \%$ do PIB do Estado até o final do século XXI.

\section{Palavras-chave}

regime de chuvas, saúde infantil, Ceará, Brasil.

Códigos JEL I15, Q54. 


\section{Introdução}

As mudanças climáticas representam um dos grandes desafios para a humanidade no século XXI, cujos prognósticos indicam aumento da temperatura global e dos níveis dos oceanos. Como consequência, diversos países podem experimentar condições meteorológicas adversas, tais como mudanças nos padrões de chuvas, ondas de frio e calor e aumento das ocorrências de secas e inundações (UNDP, 2009), ampliando ainda mais as desigualdades econômicas e sociais no mundo (Costello et al., 2009).

As projeções de mudanças climáticas do Intergovernmental Panel on Climate Change - IPCC (2012) colocam o Nordeste brasileiro como uma das regiões do globo a experimentar aumentos da intensidade e da duração das secas. Concomitante, o Painel Brasileiro de Mudanças Climáticas indica que o Nordeste poderá apresentar aumento médio de $0,5^{\circ} \mathrm{C}$ a $1^{\circ} \mathrm{C}$ na temperatura do ar e decréscimo médio de até $20 \%$ no nível de precipitação pluviométrica até 2040 (PBMC, 2012), podendo gerar efeitos adversos para a região, como perda de produtividade (Assunção; Chen, 2016) e aumento da taxa de mortalidade de crianças menores de 5 anos e vida (Souza et al., 2013). ${ }^{1}$ Particularmente, a saúde da população da região Nordeste tende a ser vulnerável às mudanças climáticas em função da combinação de condições socioeconômicas ruins e da predominância do clima semiárido, o qual é propenso às variações climáticas extremas e à persistência de doenças infecciosas endêmicas na região (Confalonieri; Rodriguez, 2009).

O estado do Ceará, objeto do presente estudo, possui quase $87 \%$ de seu território na região semiárida do Nordeste. Além disso, mais da metade de sua população (55\%) vive com uma renda domiciliar per capita menor do que meio salário mínimo ( $\mathrm{R}$ \$255,00/mês, ou $\mathrm{R}$ \$ 8,5/dia, em valores de 2010), a quinta maior taxa de pobreza do país em 2010. Tais características estão historicamente associadas à vulnerabilidade do Ceará aos períodos de seca (Lindoso et al., 2014).

Nesse contexto, torna-se fundamental investigar como a saúde de grupos demográficos vulneráveis, como é o caso de crianças menores de 5 anos de vida, é afetada pela escassez de chuvas no Ceará. Logo, o presente estudo se propõe a apresentar estimativas de impactos da precipitação plu1 Souza et al. (2013) estimam que o custo monetário das mortes decorrentes das mudanças climáticas poderá chegar a 4,7\% do Produto Interno Bruto do Brasil. 
viométrica $(\mathrm{mm})$ sobre a saúde infantil nos municípios cearenses nos anos censitários de 1991, 2000 e 2010 e projetar os custos monetários decorrentes da perda de vida para diferentes cenários de mudanças climáticas. Para tanto, utiliza-se a taxa de mortalidade de crianças menores de 5 anos de vida (TMC) como medida de saúde infantil.

É importante ressaltar que o Ceará apresentou queda de aproximadamente 75\% nesse indicador entre 1991 e 2010 (saindo de 82,7 para 20,8 por mil nascidos vivos). Diversos fatores podem ter contribuído para tal redução, por exemplo: melhorias nas condições socioeconômicas (Alves; Belluzzo, 2004), acesso a água potável (Gamper-Rabindran et al., 2010), descentralização dos serviços de atenção básica (Rocha; Soares, 2010) e transferência condicionada de renda para famílias pobres (Rasella et al., 2013). Ademais, esses fatores podem ter contribuído também para aumentar a resiliência da população cearense aos períodos de seca.

A literatura também tem apontado evidências das consequências dos fenômenos climáticos sobre a saúde infantil, principalmente relacionando a escassez de chuvas à desnutrição e à mortalidade (Hoddinott; Kinsey, 2001; Bauer; Mburu, 2017). As evidências também mostram que o excesso de chuvas pode provocar a desnutrição infantil, como ocorreu no México em 1999, provocado pelo aumento da incidência de doenças infecciosas, e não pelo baixo consumo de calorias (Skoufias; Vinhas, 2012). Ademais, a escassez de chuvas no semiárido nordestino durante o período intrauterino aumenta as chances de óbito de crianças antes do primeiro ano de vida, em função da desnutrição e das infecções intestinais (Rocha; Soares, 2015). Outros estudos têm investigado as implicações das variações extremas na temperatura do ar durante o período gestacional sobre os indicadores de saúde ao nascer e nutricionais (Deschênes et al., 2009; Pereda et al., 2014; Groppo; Kraehnert, 2016; Andalón et al., 2016).

Em geral, esses estudos buscam verificar se os principais mecanismos que intermediam os efeitos das mudanças climáticas sobre a saúde infantil estão alicerçados na exposição às doenças infecciosas e à desnutrição, as quais se configuram como as principais causas de morte de crianças com idade inferior a 5 anos no mundo (Cutler et al., 2006). No entanto, outros mecanismos podem interagir com a exposição às doenças infecciosas e à desnutrição, tornando mais complexa a análise de mecanismo (Confalonieri et al., 2007; Stank et al., 2013; Phalkey et al., 2015). Esse é o caso dos processos migratórios, os quais refletem a resposta da população aos even- 
tos climáticos extremos (Deschênes; Moretti, 2009; Barbieri et al., 2010; Delazeri; Cunha, 2015).

Os resultados do presente estudo corroboram a literatura internacional supracitada, mostrando que municípios cearenses com baixa pluviometria apresentam, em média, maior taxa de mortalidade de crianças menores de 5 anos de vida. As estimativas indicam que uma queda de 1 desvio padrão na precipitação média dos municípios implica aumento de aproximadamente 10 óbitos de crianças menores de 5 anos para cada mil nascidas vivas. Essa relação negativa é explicada, especialmente, pela ocorrência de episódios de seca severa/extrema nos municípios, cujos efeitos são mediados pela maior incidência de doenças infecciosas. Além disso, as projeções de impacto indicam que os custos monetários em decorrência da perda de capital humano antes do quinto ano de vida poderão chegar até 1,5\% do Produto Interno Bruto (PIB) Estadual até o final do século XXI.

Portanto, as evidências empíricas apresentadas no presente estudo contribuem para a literatura econômica dedicada a analisar os efeitos de choques climáticos sobre a saúde infantil no Brasil (Souza et al., 2013; Pereda et al., 2014; Rocha; Soares, 2015). Tais estudos são relevantes por proporcionarem melhor entendimento dos mecanismos de efeitos, os quais podem ajudar os formadores de políticas públicas na elaboração de soluções práticas com foco na adaptação e/ou resposta aos eventos climáticos extremos no Ceará.

O estudo está dividido em seis seções. A Seção 1 corresponde à Introdução, já devidamente apresentada. A Seção 2 descreve as bases de dados, enquanto a Seção 3 detalha a estratégia empírica adotada. A Seção 4 apresenta os resultados estimados. A Seção 5 discute as limitações do estudo e, finalmente, a Seção 6 apresenta a conclusão.

\section{Base de dados}

Neste estudo, utilizam-se dados do Atlas do Desenvolvimento Humano no Brasil (2013), produzido pelo Programa das Nações Unidas para o Desenvolvimento no Brasil, como principal fonte de informação. Além da taxa de mortalidade de crianças menores que 5 anos de vida, outros importantes indicadores podem ser acessados nessa base de dados em nível de municípios, permitindo observar diferenças nos níveis de desenvolvimento socioeconômico entre as unidades observacionais e a evolução dos indi- 
cadores ao longo de duas décadas. A amostra total é de 552 observações, correspondendo aos 184 municípios cearenses em três anos censitários (1991; 2000; 2010).

A segunda fonte de informações diz respeito à base de dados Terrestrial Air Temperature and Precipitation: 1900-2014 Gridded Monthly Time Series (Version 4.01), da Universidade de Delaware, Estados Unidos. A respectiva fonte de informações fornece o valor mensal da precipitação pluviométrica $(\mathrm{mm})$ e da temperatura do $\operatorname{ar}\left({ }^{\circ} \mathrm{C}\right)$ para uma grade de latitude e longitude de $0,5 \times 0,5$ graus, ou $56 \times 56$ quilômetros (Willmott; Matsuura, 2014a, b). As próximas subseções apresentam de forma detalhada as variáveis provenientes dessas duas fontes de dados.

\subsection{A taxa de mortalidade de menores de 5 anos de vida}

O Atlas do Desenvolvimento Humano no Brasil (2013) mostra evolução significativa dos municípios cearenses quanto à saúde infantil, mensurada pela taxa de mortalidade de crianças menores de 5 anos de vida (TMC). Em 1991, a média entre os municípios era de 92,1 óbitos por mil nascidos vivos (desvio padrão $=15,8$ ), reduzindo-se para 60,5 por mil nascidos vivos no ano 2000 (desvio padrão $=11,0$ ), e atingindo 26,5 por mil nascidos vivos em 2010 (desvio padrão $=4,0$ ).

Vale ressaltar que o Gráfico 1 mostra não somente uma menor mediana da distribuição dos valores por municípios em anos censitários, como também substancial redução na dispersão dos mesmos.

Gráfico 1 Diagramas de caixa para a taxa de mortalidade para menores de 5 anos de vida

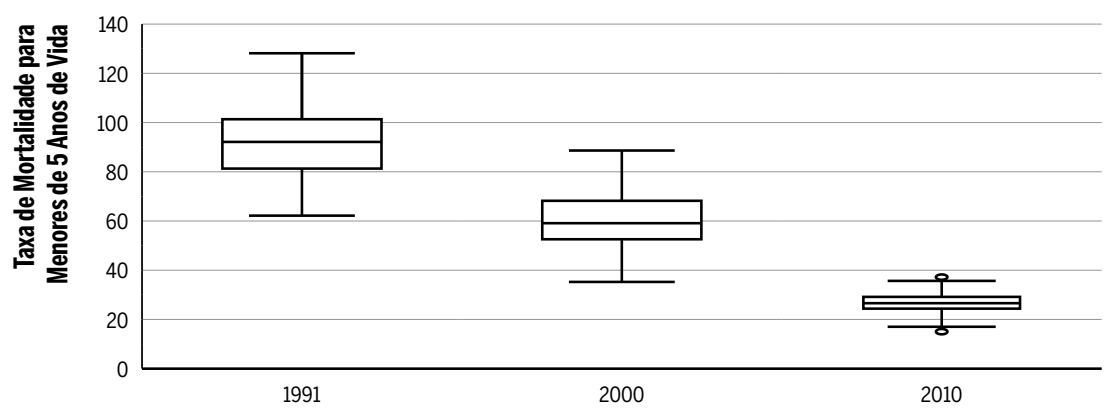

Fonte: Elaboração dos autores. 
Em particular, programas focados na população pobre que, via de regra, está mais exposta às doenças e possui menos acesso aos nutrientes, podem ter contribuído para a redução da dispersão. Esse é o caso do Programa Bolsa Família (Rasella et al., 2013) e do Programa Saúde da Família (Rocha; Soares, 2010), os quais foram expandidos sobremaneira durante a década de 2000.

Na próxima subseção, descrevemos as principais variáveis socioeconômicas e demográficas, as quais capturam a melhoria do padrão de vida da população dos municípios, podendo, portanto, ter contribuído para a queda da TMC no Ceará no período analisado.

\subsection{Condicionantes socioeconômicos e demográficos}

As mudanças observadas nas condições socioeconômicas e demográficas podem, não somente ter contribuído para a redução da TMC (ver Gráfico 1), como também podem ter ajudado a definir o grau de vulnerabilidade dos municípios frente à escassez de chuvas. Por conseguinte, torna-se fundamental a inclusão dessas variáveis como controles adicionais nas regressões, cuja variável de interesse é a precipitação pluviométrica municipal.

Estudos sobre os determinantes da taxa de mortalidade infantil no Brasil mostram que a renda per capita, a educação e o saneamento básico contribuíram substancialmente para a redução dos óbitos infantis entre as décadas de 1970 e 2000 (Alves; Beluzzo, 2004). No caso do Ceará, Irff e Barbosa (2008) mostram que, entre 1991 e 2000, a taxa de mortalidade infantil é especialmente sensível à renda per capita e à taxa de pobreza.

$\mathrm{Na}$ Tabela 1, observa-se que a média da renda domiciliar per capita apresentou crescimento real de $136 \%$ entre 1991 e $2010 .^{2}$ Esse crescimento da renda per capita municipal pode ter contribuído para melhor suavização do consumo por parte da população, em especial o de alimentos, em períodos de seca.

No entanto, a desigualdade de renda nos municípios cearenses não melhorou no mesmo período. Embora o período de 2000 a 2010 tenha sido festejado com a tendência clara de queda da desigualdade de renda no Brasil (saindo de 0,64 para 0,60), a década da estabilização econômica havia segundo o Atlas do Desenvolvimento Humano 2013. 
deixado um legado de elevação da desigualdade de renda (saindo de 0,63 para 0,64), segundo o Atlas do Desenvolvimento Humano no Brasil (2013). No Ceará, o valor médio do Gini para os municípios havia aumentado de 0,53 para 0,59 entre 1991 e 2000, mas retornou ao valor de 0,53 em 2010.

Tabela 1 Valores médios e desvio padrão das características socioeconômicas e demográficas municipais.

\begin{tabular}{|c|c|c|c|}
\hline \multirow{2}{*}{ Variáveis Explicativas } & \multicolumn{3}{|c|}{ Anos Censitários } \\
\hline & 1991 & 2000 & 2010 \\
\hline Renda domiciliar per capita $(\mathrm{R} \$)$ & $\begin{array}{r}113,29 \\
(42,78)\end{array}$ & $\begin{array}{r}163,46 \\
(55,64)\end{array}$ & $\begin{array}{r}267,64 \\
(76,34)\end{array}$ \\
\hline Índice de Gini (0-1) & $\begin{array}{r}0,53 \\
(0,06) \\
\end{array}$ & $\begin{array}{r}0,59 \\
(0,05) \\
\end{array}$ & $\begin{array}{r}0,53 \\
(0,05)\end{array}$ \\
\hline Proporção de pobres (\%, RDPC $\leq \mathrm{R} \$ 225,00)$ & $\begin{array}{r}92.60 \\
(4.36)\end{array}$ & $\begin{array}{l}84.86 \\
(5.58)\end{array}$ & $\begin{array}{l}67.88 \\
(7.81)\end{array}$ \\
\hline Taxa de analfabetismo (18 anos ou mais) & $\begin{array}{l}50,63 \\
(7,88)\end{array}$ & $\begin{array}{r}37,75 \\
(6,80)\end{array}$ & $\begin{array}{l}29,60 \\
(6,14)\end{array}$ \\
\hline Taxa de fecundidade total & $\begin{array}{r}4,59 \\
(0,90)\end{array}$ & $\begin{array}{r}3,37 \\
(0,59)\end{array}$ & $\begin{array}{r}2,28 \\
(0,30)\end{array}$ \\
\hline Taxa de urbanização (\%) & $\begin{array}{r}42,62 \\
(18,07)\end{array}$ & $\begin{array}{r}51,07 \\
(16,75)\end{array}$ & $\begin{array}{r}56,38 \\
(15,68)\end{array}$ \\
\hline $\begin{array}{l}\text { Pessoas morando em domicílios com água canalizada } \\
(\%)\end{array}$ & $\begin{array}{r}20,07 \\
(14,07)\end{array}$ & $\begin{array}{r}39,68 \\
(15,41)\end{array}$ & $\begin{array}{r}76,11 \\
(12,47)\end{array}$ \\
\hline $\begin{array}{l}\text { Pessoas morando em domicílios com acesso inadequa- } \\
\text { do ao abastecimento de água e coleta de esgoto (\%) }\end{array}$ & $\begin{array}{r}52.53 \\
(21.59)\end{array}$ & $\begin{array}{r}20.50 \\
(12.83)\end{array}$ & $\begin{array}{r}17.51 \\
(9.95)\end{array}$ \\
\hline $\begin{array}{l}\text { Pessoas vivendo em domicílios com mais de dois mora- } \\
\text { dores por Cômodo (\%) }\end{array}$ & $\begin{array}{r}58,67 \\
(6,42)\end{array}$ & $\begin{array}{l}48,28 \\
(6,41)\end{array}$ & $\begin{array}{l}34,86 \\
(6,05)\end{array}$ \\
\hline
\end{tabular}

Fonte: Elaboração dos autores.

Uma das razões para o Ceará não ter experimentado uma redução mais forte no referido indicador entre 2000 e 2010 está relacionada à persistência da elevada desigualdade da renda do trabalho, a qual respondia por pouco mais de 70\% do total da renda domiciliar. Miro et al. (2011) mostram que a renda do trabalho contribuiu muito pouco para a queda da desigualdade de renda no Ceará na década de 2000. Contudo, a pobreza experimentou queda substancial entre 1991 e 2010 , saindo de $92,6 \%$ para $67,9 \%$ da população. Particularmente, as transferências governamentais de renda desempenharam papel preponderante na redução da pobreza do Ceará. 
A queda da taxa de mortalidade das crianças menores de 5 anos de vida pode ter sido também influenciada pela melhoria da educação da população. A Tabela 1 mostra que a média da taxa de analfabetismo da população adulta (18 anos ou mais) entre os municípios cearenses saiu de 50,63\% em 1991 para 29,6\% em 2010. A educação, especialmente das mulheres, contribui para o melhor cuidado com a saúde da criança, sendo, portanto, um importante preditor da taxa de mortalidade de crianças menores de 5 anos de vida (Cutler et al., 2006).

Observou-se também uma queda considerável na taxa de fecundidade nos municípios cearenses, saindo de 4,59 em 1991 para 2,28 em 2010. A expectativa é de que um número menor de filhos permita que a mulher se dedique mais ao mercado de trabalho e, com um nível de educação mais elevado, passe a investir mais na formação do capital humano dos filhos (Almond; Currie, 2011). Soma-se a isso a possibilidade de a taxa de fecundidade ser sensível às mudanças climáticas, seja por conta de fatores biológicos (Fisch et al., 2003), ou por resposta comportamental aos eventos climáticos extremos (Barreca et al., 2015), sugerindo que a omissão dessa variável controle pode enviesar o impacto da flutuação das chuvas sobre a TMC.

Ademais, a população cearense passou a viver mais nas zonas urbanas dos municípios, que passou a ofertar uma melhor infraestrutura de acesso à água e ao saneamento básico. A Tabela 1 mostra que a taxa de urbanização cresceu 32,3\% entre 1991 e 2010, enquanto a proporção de pessoas vivendo em domicílios com infraestrutura inadequada de abastecimento de água (sem acesso à água proveniente da rede geral) e de coleta de esgoto (sem acesso à rede coletora ou fossa séptica) caiu $66,7 \%$ no mesmo período.

Finalmente, observou-se que a proporção de pessoas vivendo em domicílios com mais de dois membros por cômodo caiu de aproximadamente 58,8\% em 1991 para 34,9\% em 2010. Essa evidência reflete uma tendência demográfica de mobilidade social ascendente no Brasil desde 1994, concomitante ao aumento da diversidade dos arranjos familiares (Alves; Cavenaghi, 2012).

Realizada a devida caracterização geral dos municípios cearenses quanto aos condicionantes socioeconômicos e demográficos da TMC, a próxima subseção descreve o regime pluviométrico dos municípios cearenses, bem como o comportamento da temperatura do ar. 


\subsection{Precipitação pluviométrica e temperatura do ar}

As séries mensais de precipitação pluviométrica e temperatura do ar, disponibilizadas originalmente para uma grade de latitude e longitude de $0,5 \mathrm{x}$ 0,5 graus por Willmott e Matsuura (2014a, b), foram transformadas em séries mensais em nível de municípios. Para tanto, computou-se a média ponderada pelo inverso da distância com base nas latitudes e longitudes mais próximas em relação ao centroide de cada município. A partir das séries de precipitação foram obtidos os valores acumulados nos 12 meses de cada ano para os 184 municípios cearenses. No caso da temperatura do ar, tomou-se a média dos 12 meses de cada ano para as respectivas unidades observacionais.

O Gráfico 2 mostra a sazonalidade mensal da média histórica da precipitação $(\mathrm{mm})$ e da temperatura do ar $\left({ }^{\circ} \mathrm{C}\right)$ por municípios entre 1980 e 2010. A amplitude vertical de cada caixa representa a variabilidade do respectivo indicador entre os 184 municípios cearenses.

No Gráfico 2(a), percebe-se que o volume de chuvas no Ceará é mais intenso nos meses de março e abril, cuja mediana dos municípios está em torno de $200 \mathrm{~mm}$. Entre junho e novembro, o volume de chuvas cai drasticamente, chegando a quase zero no mês de setembro. Em dezembro, um novo ciclo pluviométrico se inicia e atinge seu ápice no mês de março do ano subsequente. Por outro lado, no Gráfico 2(b), a temperatura do ar descreve uma sazonalidade mensal oposta ao da precipitação pluviométrica. Ela é decrescente entre janeiro e julho, voltando a crescer entre agosto e dezembro.

O Gráfico 3, por sua vez, exibe os diagramas de caixa (ou de extremos e quartis) para o volume total de precipitação anual $(\mathrm{mm})$ e para a média anual da temperatura $\left({ }^{\circ} \mathrm{C}\right)$ dos municípios cearenses no período de 1980 a 2010. Novamente, a amplitude vertical de cada caixa revela a variabilidade dos respectivos indicadores entre os 184 municípios em cada ano da série. A linha tracejada corresponde à média histórica anual no período, cujo valor é de aproximadamente $875,1 \mathrm{~mm}$ (desvio padrão $=348$ ) para precipitação pluviométrica e $26,2^{\circ} \mathrm{C}$ (desvio padrão $=1,15$ ) para a temperatura do ar.

No Gráfico 3(a), há uma considerável variabilidade na precipitação média ao longo dos anos ( $\mathrm{CV}=0,398)$, especialmente nos primeiros anos das décadas de 1980 e 1990, quando ocorreram severos períodos de seca (1980-1983 e 1990-1993). Todavia, a temperatura do ar apresenta uma menor variabilidade de valores ao longo dos anos, onde a maior parte dos municípios apresentam médias entre $24^{\circ} \mathrm{C}$ e $28^{\circ} \mathrm{C}(\mathrm{CV}=0,044)$. 
Gráfico 2 Diagramas de caixa para a média histórica mensal da precipitação pluviométrica e da temperatura do ar dos municípios cearenses entre 1980 e 2010

\section{a Precipitação pluviométrica $(\mathrm{mm})$}

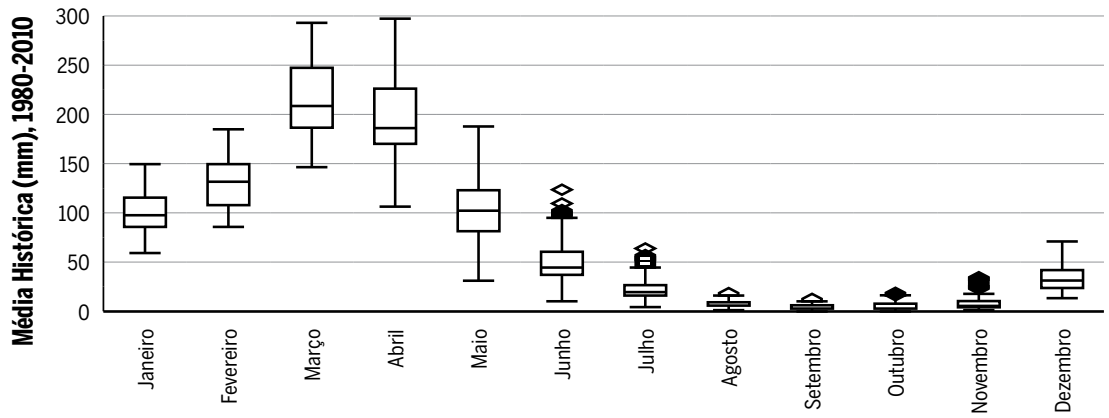

\section{b Temperatura do ar $\left({ }^{\circ} \mathrm{C}\right)$}

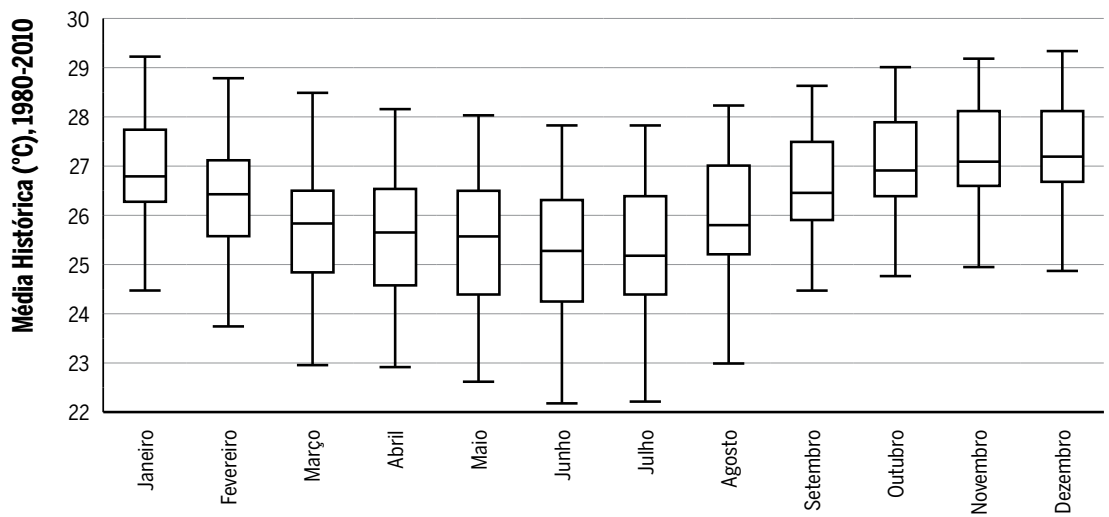

Fonte: Elaboração dos autores.

No intuito de identificar os meses (ou episódios) com escassez de chuvas para os municípios cearenses, adotou-se o Índice de Precipitação Padronizado (IPP) desenvolvido por McKee et al. (1993). ${ }^{3}$ Para cada município, classificaram-se os meses do ano como seca severa ou extrema $(I P P \leq-1,5)$,

3 Este é um dos mais comuns índices de monitoramento dos regimes de chuvas utilizado no mundo. O Instituto Nacional de Pesquisas Espaciais (INPE) e o Instituto Nacional de Meteorologia (INMET) calculam o referido índice para o território nacional. Ver Apêndice A1 para maiores detalhes a respeito do cálculo do índice. 
seca moderada $(-1,0 \leq I P P<-1,5)$, seca incipiente $(0,0 \leq I P P<-1,0)$, umidade incipiente $(0,0<I P P<1,0)$, umidade moderada $(1,0 \leq I P P<1,5)$, umidade severa ou extrema $(I P P \geq 1,5)$.

Gráfico 3 Diagramas de caixa para a média anual de precipitação $(\mathrm{mm})$ e temperatura do $\operatorname{ar}\left({ }^{\circ} \mathrm{C}\right)$ dos municípios cearenses entre 1980 e 2010

\section{a Precipitação pluviométrica $(\mathrm{mm})$}

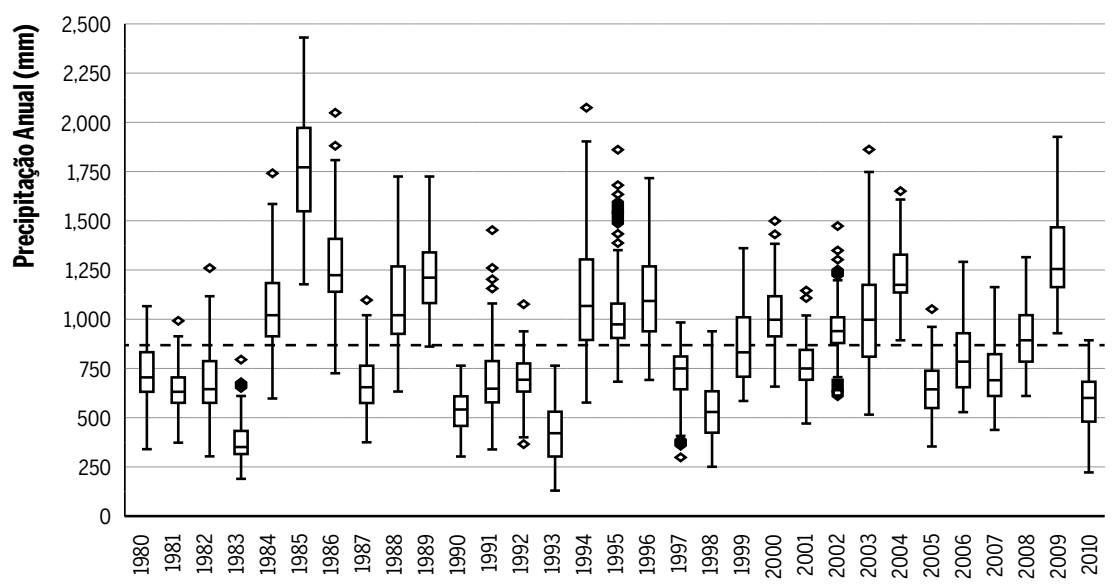

b Temperatura do ar $\left({ }^{\circ} \mathrm{C}\right)$

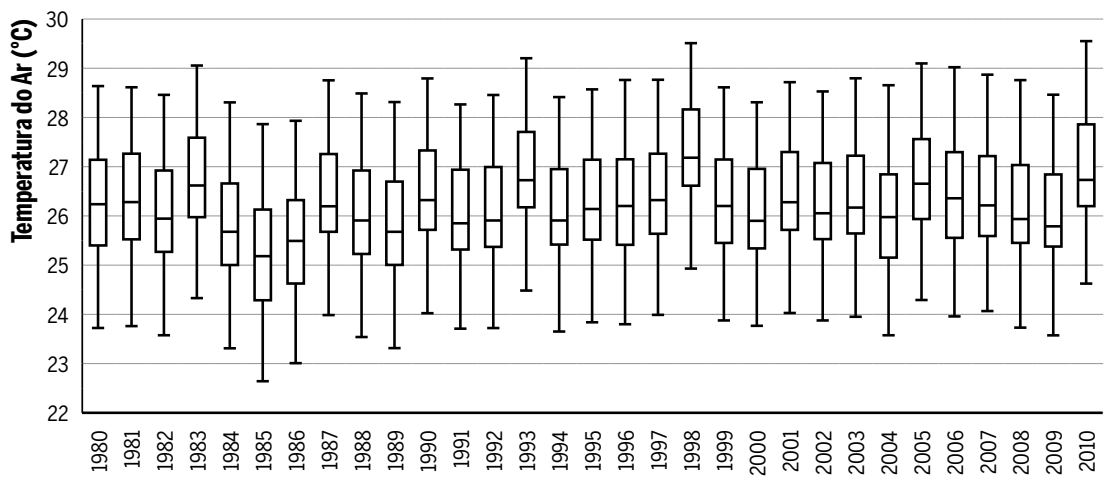

Fonte: Elaboração dos autores.

O Gráfico 4 ilustra a média de meses de cada categoria de regime pluviométrico no período de 1980 a 2010 para os municípios cearenses. Percebe- 
-se que o regime de umidade moderada raramente supera a média de um mês ao ano. Enquanto a umidade incipiente pode chegar a quatro meses em determinados anos.

Contudo, a escassez de chuvas é predominante entre os municípios cearenses na maior parte do ano. O número médio de meses de seca incipiente varia de 4 a 9 meses, enquanto o regime de seca moderada varia de um a três meses no ano. Os meses de seca severa ou extrema podem chegar a três meses em um ano. Particularmente, a década de 2000 apresenta média mais elevada de meses com seca severa/extrema entre os municípios cearenses do que as décadas de 1980 e 1990.

Gráfico 4 Número médio de meses de acordo com a classificação do regime de pluviométrico com base no Índice de Precipitação Padronizado

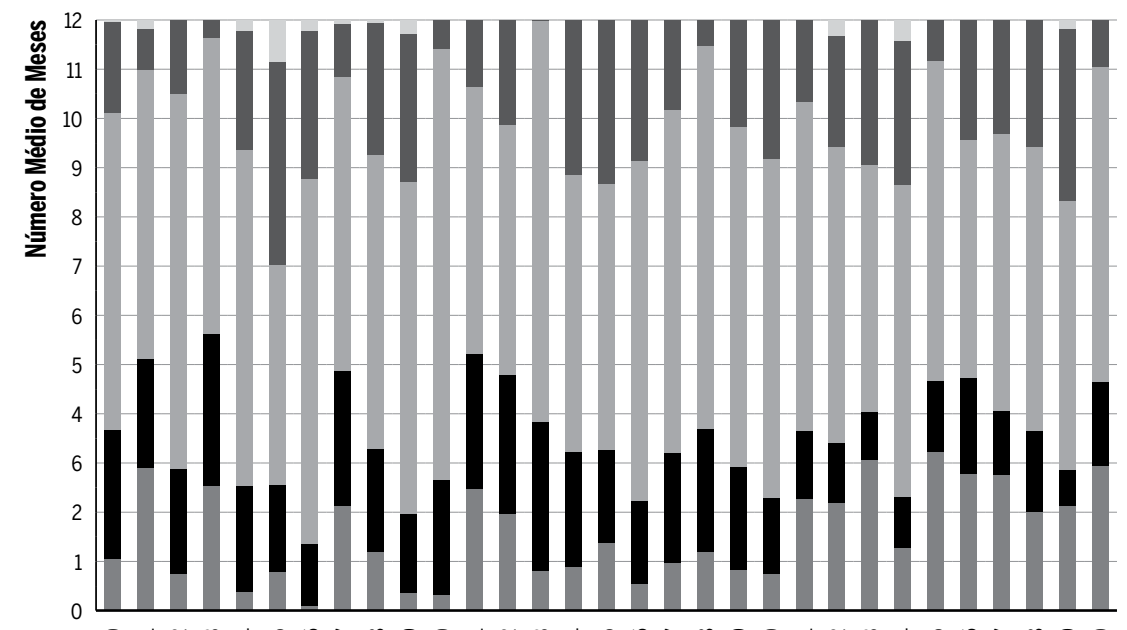

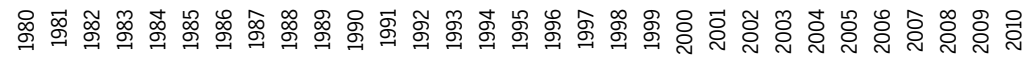

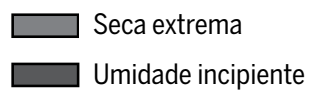

Seca moderada

$\square$ Seca incipiente

Fonte: Elaboração dos autores .

Tomando-se em conta o detalhamento das variáveis do estudo e os fatos estilizados apresentados, a próxima seção detalha a estratégia empírica e a forma como a precipitação pluviométrica $(\mathrm{mm})$ e a temperatura do $\operatorname{ar}\left({ }^{\circ} \mathrm{C}\right)$ são incluídas no modelo econométrico. 


\section{Estratégia empírica}

A estratégia empírica está fundamentada na estimação do seguinte modelo empírico:

$$
T M C_{i t}=\alpha+\rho P_{i t}+\delta T_{i t}+X_{i t} \beta+\theta_{i}+\theta_{t}+\varepsilon_{i t}
$$

onde $T M C_{i t}$ é a taxa de mortalidade de crianças menores de 5 anos de vida do município $i$ no ano censitário $t, P_{i t}$ é a pluviometria em milímetros $(\mathrm{mm})$ e $T_{i t}$ é a média anual da temperatura do ar em graus centígrados $\left({ }^{\circ} \mathrm{C}\right)$. O vetor $X_{i t}$ é composto por variáveis socioeconômicas e demográficas (ver Tabela 1). Os termos $\theta_{i}$ e $\theta_{t}$ capturam os efeitos fixos dos municípios e do tempo. $\bigcirc$ erro aleatório, $\varepsilon_{i t}$ é assumido ser distribuído normalmente com média zero e variância finita.

Vale salientar que a taxa de mortalidade para crianças menores de 5 anos de vida, por envolver diversas coortes de nascimentos em seu cálculo, pode ser sensível às variações na precipitação pluviométrica municipal em anos precedentes ao ano censitário de referência (1991; 2000; 2010). ${ }^{4}$ Assim, definiu-se como variável de interesse o valor médio da precipitação pluviométrica municipal em um período de cinco anos, incluindo o ano censitário (1987-1991, 1996-2000 e 2006-2010). Implicitamente, assume-se que as crianças de determinado município estão expostas às mesmas condições climáticas nos últimos cinco anos em relação ao ano censitário de referência. A partir dessa suposição, estimam-se também os efeitos dos episódios de seca (meses com seca incipiente, moderada, ou severa/extrema) sobre a TMC.

Se, por hipótese, a mortalidade de crianças menores de cinco anos de vida é sensível à ocorrência de episódios de secas severas ou extremas, podemos esperar uma associação positiva entre a TMC e o número de episódios de seca no período de cinco anos, corroborando uma potencial

4 Embora a taxa de mortalidade de crianças menores de um ano de vida também esteja disponível no Atlas do Desenvolvimento Humano 2013, optou-se por não usá-la como variável dependente no presente estudo. A razão é que a TMI agrega coortes de nascimento do ano de referência ou do ano anterior ao censo demográfico, reduzindo as chances de capturar os efeitos dos episódios de seca severa/extrema. Utilizando a taxa de mortalidade de crianças menores de 5 anos de vida, não somente as coortes de crianças nascidas no ano de referência são incluídas no cálculo da TMC, como também as coortes de nascimento de até cinco anos anteriores ao ano censitário. Assim, amplia-se a possibilidade de capturar melhor os efeitos dos episódios de seca usando a TMC no lugar da TMI. 
relação negativa entre a TMC e a precipitação pluviométrica. Para verificar tal hipótese, estima-se o seguinte modelo:

$$
T M C_{i t}=\alpha+\phi_{1} S E_{i t}+\phi_{2} S M_{i t}+\phi_{3} S I_{i t}+\delta T_{i t}+X_{i t} \beta+\theta_{i}+\theta_{t}+\varepsilon_{i t}
$$

onde $S E_{i t}$ é o número de meses de seca severa/extrema no município $i$ no período de cinco anos em relação ao ano censitário $t, S M_{i t}$ é o número de meses de seca moderada no município $i$ no período de cinco anos em relação ao ano censitário $t$ e $S I_{i t}$ é o número de meses de seca incipiente (ou suave) no município $i$ no período de cinco anos em relação ao ano censitário $t$. Os parâmetros $\varphi_{1}, \varphi_{2}$ e $\varphi_{3}$ capturam as diferenças na TMC quanto ao número de episódios de seca em relação aos meses com umidade (ou seja, IPP $>0$ ).

Ademais, a identificação dos modelos (1) e (2) assume que os efeitos fixos em nível de municípios, $\theta_{i}$ capturam suas características não observáveis e imutáveis ao longo do tempo. Tais características latentes podem influenciar a mortalidade de crianças menores de 5 anos de vida, bem como se correlacionarem com a precipitação pluviométrica do município (exemplo, disponibilidade natural de recursos hídricos). Por outro lado, os efeitos fixos associados ao tempo, $\theta_{t}$ capturam choques agregados sobre os municípios cearenses, bem como a tendência histórica decrescente da TMC.

Também se estimam os modelos (1) e (2) incluindo controles adicionais (ver Tabela 1) no intuito de controlar possíveis diferenças municipais quanto à vulnerabilidade socioeconômica aos eventos climáticos extremos. Além disso, especificações alternativas são testadas com o objetivo de verificar a robustez dos resultados. Por exemplo, estima-se o modelo (1) substituindo a precipitação pluviométrica dos municípios (mm) pelo Índice Padronizado de Precipitação (IPP), o qual mede os desvios da precipitação municipal em relação à média histórica em termos de desvios padrões. Outra versão do modelo (1) é estimada, mas incluindo a variável dependente defasada. Essa abordagem permite controlar por potenciais variáveis omitidas que variam no tempo (Angrist; Pischke, 2009). Realiza-se também uma análise "placebo" para testar a robustez das estimativas.

O presente estudo também busca investigar os possíveis mecanismos de efeito da precipitação pluviométrica sobre a TMC. Primeiro, testa-se a hipótese da disponibilidade de alimentos como canal mediador do efeito da precipitação pluviométrica sobre a TMC dos municípios. Em seguida, 
analisam-se quais causas de morte de crianças menores de 5 anos de vida (nesse caso, doenças infecciosas e desnutrição) são mais sensíveis ao regime de chuvas dos municípios. Diante do exposto, a próxima seção apresenta os resultados das estimações propostas.

\section{Resultados}

\subsection{Resultados básicos}

Esta subseção apresenta os efeitos da precipitação pluviométrica $(\mathrm{mm})$ média dos últimos cinco anos, incluindo o ano censitário (1987-1991, 19962000 e 2006-2010). As especificações variam dependendo da inclusão de controles adicionais ao modelo como é o caso da temperatura do ar $\left({ }^{\circ} \mathrm{C}\right)$ e das variáveis socioeconômicas e demográficas. A Tabela 2 apresenta as estimativas do modelo empírico (1).

Tabela 2 Estimativas para a precipitação pluviométrica

\begin{tabular}{lrrrr}
\hline & (1) & (2) & (3) \\
\hline Precipitação (mm) & ${ }^{* *}-0,031$ & ${ }^{* *}-0,034$ & ${ }^{* *}-0,030$ \\
& $(0,013)$ & $(0,013)$ & $(0,014)$ \\
\hline Controles adicionais & & & \\
\hline Temperatura do ar $\left({ }^{\circ} \mathrm{C}\right)$ & Não & Sim & Sim \\
\hline Socioeconômicos e demográficos & Não & Não & Sim \\
\hline $\mathbf{N}$ & 552 & 552 & 552 \\
\hline
\end{tabular}

Nota: Erro padrão robusto e clusterizado em nível de municípios aparec e entre parênteses. Todas as estimações incluem os efeitos fixos de municípios (183 dummies) e de ano (2 dummies). Os controles socioeconômicos e demográficos municipais $(X)$ incluem as seguintes variáveis: log natural da renda domiciliar per capita, índice de Gini, taxa de fecundidade, taxa de analfabetismo para a população maior de 18 anos de idade, taxa de urbanização, proporção de pessoas vivendo em domicílios com mais de duas pessoas por dormitório, proporção de pessoas vivendo em domicílios com acesso a água canalizada, proporção de pessoas vivendo em domicílios com acesso inadequado ao abastecimento de água e coleta de esgoto, interação entre o indicador de municípios pobres (proporção de pobres acima do valor mediano) e dummies para os anos de 2000 e 2010. ${ }^{* *} p$-valor $<0,01$, ${ }^{* *} p$-valor $<0,05 e{ }^{*} p$-valor $<0,1$.

Os resultados da Tabela 2 mostram que a TMC se relaciona negativamente com a precipitação pluviométrica municipal. A estimação mais robusta, correspondendo à coluna (3), mostra um coeficiente negativo e estatisticamente significante ao nível de $5 \%$. A estimativa indica que uma queda de 
1 desvio padrão (=348) na pluviometria média dos municípios pode elevar a taxa de mortalidade em aproximadamente 10 óbitos para cada mil crianças nascidas vivas. Esse resultado corrobora Rocha e Soares (2015), muito embora não sejam comparáveis em termos de magnitude. ${ }^{5}$

A próxima subseção apresenta os resultados de modelos alternativos, como forma de demonstrar a sensibilidade da TMC em relação a outras variáveis associadas à precipitação pluviométrica dos municípios.

\subsection{Especificações alternativas}

Nesta subseção, busca-se verificar dois importantes aspectos relacionados aos resultados da Tabela 2, que são: i) se os episódios de seca são de fato os responsáveis pelo impacto da precipitação média sobre a TMC; e ii) se a relação negativa entre a TMC e a precipitação pluviométrica é conservada ao se utilizar o Índice Padronizado de Precipitação (IPP) em vez da precipitação pluviométrica.

\section{Efeitos dos episódios de seca}

A Tabela 3 apresenta os efeitos dos episódios de seca (incipiente, moderada, e severa/extrema) sobre a TMC. Os resultados na coluna 3 mostram que um mês adicional de seca severa/extrema eleva a taxa de mortalidade em aproximadamente um óbito de criança menor de 5 anos de vida para cada mil nascidas vivas. Esse resultado corrobora a hipótese de que são os episódios de seca severa/extrema que direcionam o impacto da precipitação pluviométrica sobre a mortalidade de crianças nos municípios cearenses.

5 Rocha e Soares (2015) utilizam os desvios da precipitação média durante a gestação em relação à média histórica municipal. Os autores mostram que um desvio negativo da precipitação média de 1 log em relação à média histórica pode aumentar a taxa de mortalidade de crianças menores de 1 ano de vida em 5,4 óbitos para cada mil nascidas vivas. 
Tabela 3 Estimativas para os episódios de secas

\begin{tabular}{lrr|r}
\hline & $\mathbf{( 1 )}$ & $\mathbf{( 2 )}$ & $\mathbf{( 3 )}$ \\
\hline Seca severa/extrema (SE) & ${ }^{* *} 0.982$ & ${ }^{* *} 1.052$ & ${ }^{* *} 1.069$ \\
& $(0.441)$ & $(0.436)$ & $(0.442)$ \\
\hline Seca moderada (SM) & 0.700 & ${ }^{*} 0.754$ & 0.652 \\
\hline Seca incipiente (SI) & $(0.447)$ & $(0.438)$ & $(0.443)$ \\
\hline Controles adicionais & 0.578 & 0.601 & 0.549 \\
\hline Temperatura do ar $\left({ }^{\circ} \mathrm{C}\right)$ & $(0.407)$ & $(0.401)$ & $(0.399)$ \\
\hline Socioeconômicos e demográficos & & & \\
\hline $\mathrm{N}$ & Não & Sim & Sim \\
\hline
\end{tabular}

Nota: Erro padrão robusto e clusterizado em nível de municípios aparece entre parênteses. Todas as estimações incluem os efeitos fixos de municípios (183 dummies) e de ano (2 dummies). A lista de variáveis controle pode ser acessada no rodapé da Tabela $2 .{ }^{* *} p$-valor $<0,01,{ }^{* *} p$-valor $<0,05 e$

${ }^{*} p$-valor $<0,1$.

\section{Efeitos a partir do índice de precipitação padronizado (IPP)}

Um resultado alternativo ao apresentado na Tabela (2) é a estimação do modelo (1), na qual se utiliza como variável explicativa o valor médio do Índice de Precipitação Padronizado (IPP) mensal dos últimos cinco anos. Pelo fato de possuir uma distribuição de valores aproximada para uma distribuição normal padrão, a interpretação dos coeficientes diz respeito ao número de desvios padrões em relação à média histórica da precipitação pluviométrica (Mckee et al., 1993). A Tabela 4 apresenta os resultados das estimações.

Tabela 4 Estimativas para o índice de precipitação padronizado

\begin{tabular}{lrrrr}
\hline & $\mathbf{( 1 )}$ & $\mathbf{( 2 )}$ & $\mathbf{( 3 )}$ \\
\hline IPP & $*^{* *}-21,547$ & $*^{* *}-22,805$ & ${ }^{* * *}-26,903$ \\
& $(6,718)$ & $(6,760)$ & $(7,014)$ \\
\hline Controles adicionais & & & \\
\hline Temperatura do ar $\left({ }^{\circ} \mathrm{C}\right)$ & Não & Sim & Sim \\
\hline Socioeconômicos e demográficos & Não & Não & Sim \\
\hline $\mathbf{N}$ & 552 & 552 & 552 \\
\hline
\end{tabular}

Nota: Erro padrão robusto e clusterizado em nível de municípios aparece entre parênteses. Todas as estimações incluem os efeitos fixos de municípios (183 dummies) e de ano (2 dummies). A lista de 
variáveis controle pode ser acessada no rodapé da Tabela $2 .{ }^{* *} p$-valor $<0,01,{ }^{* *} p$-valor $<0,05 e$ ${ }^{*} p$-valor $<0,1$.

Os resultados mostram que a TMC se relaciona negativamente com o IPP dos municípios, indicando que municípios com baixo (elevado) valor médio do índice nos últimos cinco anos apresentam maiores (menores) taxas de mortalidade de crianças menores de 5 anos de vida. $O$ coeficiente estimado na versão mais robusta do modelo é -26,9, e se mostra estatisticamente significantes ao nível de 1\%. Essa estimativa indica que uma queda de 1 desvio padrão da pluviometria média em relação à média histórica pode elevar a taxa de mortalidade em aproximadamente 27 óbitos de crianças menores de 5 anos de vida por cada mil nascidas vivas.

Portanto, os resultados desta subseção corroboram a hipótese de que a saúde infantil é, de fato, sensível às condições pluviométricas dos municípios cearenses, especialmente à ocorrência de episódios de seca severa/extrema.

\subsection{Análise de robustez}

A presente subseção apresenta estimações alternativas ao modelo (1) com o intuito de verificar a robustez dos resultados apresentados na Tabela 2. Inicialmente, estima-se uma versão do modelo (1) com variável dependente defasada e, em seguida, testa-se o modelo (1) com a inclusão de uma variável "placebo".

\section{Efeitos fixos versus variável dependente defasada}

modelo de efeitos fixos assume que a heterogeneidade não observada é constante em relação à dimensão tempo. Todavia, há a possibilidade de fatores não observáveis que variam no tempo exercerem influência sobre as estimativas, mesmo com a estimação de efeitos fixos e a inclusão de variáveis controles. Nessa situação, Angrist e Pischke (2009) sugerem, sob certas condições, a estimação de um modelo com variável dependente defasada do tipo:

$$
T M C_{i t}=\alpha+\rho P_{i t}+\delta T_{i t}+\lambda T M C_{i t-1}+\varepsilon_{i t}
$$


Dessa forma, a taxa de mortalidade defasada capturaria fatores não observáveis variantes no tempo. Ainda mais importante é o fato de as estimativas dos modelos (1) e (3) poderem ser interpretadas como limites (inferior e superior) do verdadeiro efeito causal da precipitação sobre a mortalidade de crianças menores de cinco anos de vida. ${ }^{6}$

Tabela 5 Estimativas para o modelo com variável dependente defasada

\begin{tabular}{l|r|r|r}
\hline & $\mathbf{( 1 )}$ & $\mathbf{( 2 )}$ & $\mathbf{( 3 )}$ \\
\hline Precipitação (mm) & ${ }^{* *}-0,006$ & ${ }^{* *}-0,006$ & ${ }^{* *}-0,006$ \\
& $(0,003)$ & $(0,003)$ & $(0,003)$ \\
\hline \multirow{2}{*}{ Taxa de mortalidade $(t-1)$} & ${ }^{* *} 0,810$ & ${ }^{* * *} 0,810$ & ${ }^{* * *} 0,510$ \\
& $(0,015)$ & $(0,015)$ & $(0,024)$ \\
\hline
\end{tabular}

\section{Controles adicionais}

\begin{tabular}{llll}
\hline Temperatura do ar $\left({ }^{\circ} \mathrm{C}\right)$ & Não & Sim & Sim \\
\hline Socioeconômicos e demográficos & Não & Não & Sim \\
\hline $\mathbf{N}$ & 368 & 368 & 368 \\
\hline
\end{tabular}

Nota. Erro padrão robusto e clusterizado em nível de municípios aparece entre parênteses. Todas as estimações incluem os efeitos fixos de municípios (183 dummies) e de ano (dummy para o ano de 2010). A lista de variáveis controle pode ser acessada no rodapé da Tabela 2. ${ }^{* *} p$-valor $<0,01,{ }^{* *} p$-valor $<$ $0,05 e^{*} p$-valor $<0,1$.

A Tabela 5 mostra que uma queda de 1 desvio padrão $(=348)$ na precipitação média dos municípios em um período de cinco anos resultaria em aumento de aproximadamente dois óbitos de crianças menores de 5 anos de vida por mil nascidas vivas. Essa estimativa é estatisticamente significante e cinco vezes menor do que aquela obtida no modelo de efeitos fixos. Portanto, sugere-se que o verdadeiro valor do parâmetro $\rho$ está entre $-0,030$ e $-0,006$, considerando-se os resultados da coluna (3) nas Tabelas 2 e 5.

\section{Análise "placebo" para a precipitação pluviométrica}

Nesta parte do estudo, propõe-se uma análise adicional de robustez dos resultados apresentados na Tabela $1 \mathrm{com}$ base no teste de significância de 6 Rocha e Soares (2010) estimam o modelo com a variável dependente defasada com o objetivo de analisar o impacto da expansão do Programa Saúde da Família sobre as taxas de mortalidade da população brasileira. De Oliveira e Quintana-Domeque (2014) realizam o mesmo procedimento para estimar o limite inferior e superior do impacto das condições econômicas ao nascer sobre a estatura da população adulta brasileira. 
uma variável "placebo". Testa-se a hipótese nula de inexistência de qualquer associação entre a TMC e a precipitação pluviométrica média de dois anos posteriores ao ano censitário (ou seja, 1992-1993, 2001-2002, 20112012). A Tabela 6 apresenta os resultados das estimações incluindo a variável "placebo" nas regressões.

Tabela 6 Estimativas para o modelo com variável dependente "placebo"

\begin{tabular}{lrr|r|r|r}
\hline & $\mathbf{( 1 )}$ & $\mathbf{( 2 )}$ & $\mathbf{( 3 )}$ & $\mathbf{( 4 )}$ \\
\hline Precipitação (mm) & $-0,001$ & 0,001 & $-0,002$ & $-0,002$ \\
para 2 anos posteriores & $(0,009)$ & $(0,009)$ & $(0,008)$ & $(0,008)$ \\
\hline \multirow{2}{*}{ Precipitação (mm) } & & $* *-0,031$ & $* *-0,031$ & $* * * 0,031$ \\
& & $(0,014)$ & $(0,014)$ & $(0,014)$ \\
\hline
\end{tabular}

\section{Controles adicionais}

\begin{tabular}{lllll}
\hline Temperatura do $\operatorname{ar}\left({ }^{\circ} \mathrm{C}\right)$ & Não & Não & Sim & Sim \\
\hline Socioeconômicos e demográficos & Não & Não & Não & Sim \\
\hline $\mathbf{N}$ & 552 & 552 & 552 & 552 \\
\hline
\end{tabular}

Nota: Erro padrão robusto e clusterizado em nível de municípios aparece entre parênteses. Todas as estimações incluem os efeitos fixos de municípios (183 dummies) e de ano (2 dummies). A lista de variáveis controle pode ser acessada no rodapé da Tabela 2. ${ }^{* *} p$-valor $<0,01,{ }^{*} p$-valor $<0,05 e$ ${ }^{*} p$-valor $<0,1$.

Os resultados mostram que não se pode rejeitar a hipótese nula, mostrando que a variável "placebo" não possui qualquer relevância na determinação da TMC. Além disso, as estimativas para a precipitação média no período de cinco anos se mantiveram praticamente inalteradas quando comparadas às estimativas da Tabela 2.

\subsection{Potenciais canais de efeito}

Esta subseção é dedicada à análise de dois potenciais mecanismos de efeito da precipitação pluviométrica sobre a TMC. Primeiro, analisa-se a disponibilidade de alimentos como canal mediado para o efeito da precipitação pluviométrica sobre a TMC dos municípios. Segundo, verifica-se a relação entre os óbitos de crianças menores de 5 anos de vida por desnutrição e por doenças infecciosas e a pluviometria dos municípios. 


\section{Disponibilidade de alimentos}

As mudanças climáticas decorrentes do aquecimento global poderão reduzir a produtividade agrícola do Ceará em $30 \%$, segundo Assunção e Chen (2016). Particularmente, as culturas de subsistência e a produção de grãos no Ceará são bastante sensíveis ao regime de chuvas (Suliano et al., 2009). Logo, a queda na produção agrícola decorrente da escassez de chuva e aumento da temperatura pode restringir a disponibilidade de alimentos para a população e, consequentemente, reduzir a quantidade de nutrientes necessárias para o pleno crescimento e desenvolvimento fisiológico das crianças.

A Tabela 7 apresenta as estimativas dos modelos (1), adicionando o logaritmo natural da produção per capita (toneladas por habitantes) dos principais produtos agrícolas produzidos no Ceará (cana de açúcar, mandioca, feijão, e milho). As estimativas mostram que a produção agrícola per capita possui sinal negativo em todas as estimações, mas não possui significância estatística. Por outro lado, as estimativas referentes à precipitação média apresentam coeficientes ligeiramente menores àqueles exibidos na Tabelas 2, mas permanecem robustas à inclusão da produção agrícola per capita municipal. Rocha e Soares (2015) também mostram que a precipitação pluviométrica municipal permanece robusta a inclusão da produção de alimentos nas estimações.

Tabela 7 Estimativas para o modelo com a produção de alimentos per capita

\begin{tabular}{lrrrr}
\hline & $\mathbf{( 1 )}$ & $\mathbf{( 2 )}$ & $\mathbf{( 3 )}$ \\
\hline Precipitação (mm) & ${ }^{* *}-0,029$ & ${ }^{* *}-0,032$ & ${ }^{* *}-0,028$ \\
\hline In(Produção de alimentos per capita) & $(0,013)$ & $(0,013)$ & $(0,014)$ \\
\hline Controles adicionais & $-3,088$ & $-2,442$ & $-2,718$ \\
\hline Temperatura do ar $\left({ }^{\circ} \mathbf{C}\right)$ & $(2,713)$ & $(2,762)$ & $(2,736)$ \\
\hline Socioeconômicos e demográficos & & & \\
\hline $\mathbf{N}$ & Não & Sim & Sim \\
\hline
\end{tabular}

Nota: Erro padrão robusto e clusterizado em nível de municípios aparece entre parênteses. Todas as estimações incluem os efeitos fixos de municípios (183 dummies) e de ano (2 dummies). A lista de variáveis controle pode ser acessada no rodapé da Tabela $2 .{ }^{* *} p$-valor $<0,01,{ }^{* *} p$-valor $<0,05 e$ ${ }^{*} p$-valor $<0,1$. 
Suliano et al. (2009) sugerem que a produção agrícola do Ceará vem apresentando menor dependência quanto ao regime pluviométrico na década de 2000, sendo menos suscetível aos períodos de seca. Os autores sugerem que o aumento da agricultura irrigada e o maior volume de transferências governamentais de renda para o setor rural podem ter contribuído para menor vulnerabilidade das famílias em períodos de seca. Isso pode explicar a ausência de influência da variável de disponibilidade de alimentos sobre a estimativa do efeito da precipitação pluviométrica sobre a TMC.

\section{Doenças infecciosas e parasitárias}

Outro potencial mecanismo de efeito é o aumento da exposição das crianças menores de 5 anos devido às doenças infecciosas e à desnutrição em períodos de seca. Rocha e Soares (2015) estimam os efeitos da escassez de chuvas para a taxa de mortalidade infantil por causas de morte e mostram que ambas as causas de morte são sensíveis às flutuações da precipitação pluviométrica no semiárido nordestino.

Infelizmente, a base de dados utilizada para o referido estudo não apresenta taxas de mortalidade por causas de morte, o que facilitaria nossa análise. Todavia, obteve-se no Departamento de Informática do Sistema Único de Saúde (DATASUS) a proporção dos óbitos de crianças entre 0 e 5 anos de idade com respeito à desnutrição e às doenças infecciosas para os anos de 2000 e 2010. Apesar de o DATASUS disponibilizar informações sobre óbitos de crianças menores de 5 anos de vida para o ano de 1991, a subnotificação é considerável, inviabilizando o uso das informações do referido ano.

A Tabela 8 apresenta as estimações para a proporção de óbitos de crianças por doenças infecciosas e por desnutrição.

Os resultados mostram que a desnutrição não é sensível à variação da precipitação municipal, enquanto os óbitos por doenças infecciosas tendem a aumentar em municípios com baixa precipitação pluviométrica. As estimativas indicam que uma queda de 1 desvio padrão (=348) na precipitação média dos municípios elevaria a proporção de óbitos por doenças infecciosas em 7,7 pontos percentuais, segundo o modelo mais robusto. Tais resultados corroboram as evidências apresentadas por Rocha e Soares (2015). 
Tabela 8 Impacto sobre mortes causadas por doenças infecciosas e desnutrição

\begin{tabular}{lrrrr}
\hline & $\mathbf{( 1 )}$ & $\mathbf{( 2 )}$ & $\mathbf{( 3 )}$ \\
\hline Doenças infecciosas & $* *^{*}-0,021$ & $* * *$ & $-0,029$ & $*^{* *}-0,022$ \\
Precipitação (mm) & $(0,007)$ & $(0,008)$ & $(0,008)$ \\
\hline Desnutrição & $-0,001$ & $-0,003$ & $-0,001$ \\
Precipitação (mm) & $(0,003)$ & $(0,004)$ & $(0,004)$ \\
\hline Controles adicionais & & & \\
\hline Temperatura do ar $\left({ }^{\circ} \mathrm{C}\right)$ & Não & Sim & Sim \\
\hline Socioeconômicos e demográficos & Não & Não & Sim \\
\hline $\mathbf{N}$ & 368 & 368 & 368 \\
\hline
\end{tabular}

Nota: Erro padrão robusto e clusterizado em nível de municípios aparece entre parênteses. Todas as estimações incluem os efeitos fixos de municípios (183 dummies) e de ano (dummy para o ano 2010). A lista de variáveis controle pode ser acessada no rodapé da Tabela $2 .{ }^{* *} p$-valor $<0,01,{ }^{* *} p$-valor $<$ $0,05 e^{*} p$-valor $<0,1$.

\subsection{Custos da escassez de chuvas}

Finalmente, a presente subseção analisa os potenciais cenários de impacto de escassez de chuvas decorrentes das mudanças climáticas. O Nordeste (região semiárida) pode sofrer queda da precipitação pluviométrica $(\mathrm{mm})$ de $10 \%$ a $20 \%$ até 2040 , de $25 \%$ a $35 \%$ entre 2041 e 2070 , e de $40 \%$ a $50 \%$ entre 2071 e 2100 (PBMC, 2012). Esses valores da variação da precipitação pluviométrica são utilizados na construçãode cenários para os anos de 2040, 2070 e 2100.

A partir do número médio de nascidos vivos entre 2001 e 2010 no estado do Ceará (137.276, segundo o DATASUS/Sistema de Informação sobre Nascidos Vivos - SINASC), projeta-se o número de vidas perdidas de crianças menores de 5 anos $(M)$ em função da variação da precipitação pluviométrica projetada ( $\Delta P$ ) pelo PBMC (2012). Segundo Souza et al. (2013), tem-se a seguinte formulação para o número estimado de vidas perdidas:

$$
\mathrm{M}=\frac{\# \text { Nascidos Vivos }}{1000} *(\hat{\rho} * \Delta P)
$$

onde $\hat{\rho}$ é a estimativa para o (limite inferior e superior) impacto da precipitação pluviométrica sobre a TMC (ver coluna 3 das Tabela 2 e 5). Em seguida, multiplica-se o número de vidas perdidas pelo valor estatístico de uma vida, ou seja, R\$ 650 mil em valor real de 2010 (Corbi et al., 2006). 
Finalmente, o valor total da perda é apresentado em termos de proporção do PIB estadual (R $\$ 77,9$ bilhões, valor real de 2010).

A Tabela 9 apresenta as estimativas de custo de vidas perdidas em função da queda da precipitação pluviométrica causada por mudanças climáticas. As estimativas indicam que a perda monetária de capital humano na infância pode chegar a 0,6\% do PIB Estadual até 2040,1,05\% até 2070 e $1,50 \%$ até 2100 .

Tabela 9 Custo das vidas perdidas como proporção do PIB em função da escassez de chuvas provocadas por mudanças climáticas no Ceará

\begin{tabular}{l|rrrrrrr}
\hline & \multicolumn{6}{c}{ Variação pluviométrica decorrente das mudanças climáticas } \\
\hline & & & $\mathbf{2 0 4 0}$ & $\mathbf{2 0 7 0}$ & $\mathbf{2 1 0 0}$ \\
\hline Parâmetro estimado & & $-10 \%$ & $-20 \%$ & $-25 \%$ & $-35 \%$ & $-40 \%$ & $-50 \%$ \\
\hline & $-0,006$ & 0,06 & 0,12 & 0,15 & 0,21 & 0,24 & 0,30 \\
\hline & $-0,030$ & 0,30 & 0,60 & 0,75 & 1,05 & 1,20 & 1,50 \\
\hline
\end{tabular}

Fonte: Elaboração dos autores com base nas estimações das Tabelas 2 e 5 e estimativas de variação pluviométrica decorrentes de mudanças climáticas disponibilizadas pelo PBMC (2012).

Vale salientar que essas proporções são conservadoras quanto ao valor estatístico de uma vida no Brasil, a qual pode chegar a $\mathrm{R} \$ 5$ milhões, segundo Corbi et al. (2006). Esse valor pode ser ainda maior no futuro devido à tendência decrescente da natalidade, pois um número menor de crianças significará maiores investimentos (públicos e/ou privados) na formação do capital humano, motivada pela expectativa de geração de mais riqueza quando adultos.

\section{Limitações do estudo}

A principal limitação do estudo é a ausência de evidência que possa comprovar que os resultados apresentados na Seção 4 não são influenciados pela potencial migração seletiva decorrente das mudanças no padrão de chuvas no Ceará. No entanto, algumas considerações podem ser feitas com base na literatura recente e em algumas evidências apresentadas no presente estudo.

Alguns estudos recentes têm apresentado evidências dos efeitos das mudanças climáticas sobre os movimentos populacionais no Brasil. Por 
exemplo, Barbieri et al. (2010) mostram que a região central do Nordeste poderá experimentar movimentos migratórios decorrentes de mudanças climáticas, especialmente os municípios dependentes da atividade agrícola. Na mesma linha, Delazeri e Cunha (2015) fornecem indícios de que a elevação na temperatura média $\left({ }^{\circ} \mathrm{C}\right)$ e a queda na precipitação média $(\mathrm{mm})$ dos municípios do semiárido nordestino estimularam a migração rural-urbana entre 1991 e 2010. Logo, se a migração (inter-regional ou rural-urbana) da população cearense estiver condicionada ao regime de chuvas no estado, então as estimativas do modelo (1) podem estar enviesadas.

Entretanto, Queiroz e Baeninger (2013) mostram que o fluxo migratório do estado do Ceará sofreu reversão entre as décadas de 1990 e 2000. Nos anos 2000, o Ceará saiu da condição de estado "emissor" para "receptor". Muito provavelmente, tal mudança no padrão migratório do Ceará nesse período não foi influenciada pelos eventos climáticos extremos, mas sim pela melhoria das condições socioeconômicas observadas nesse período (ver Tabela 1). Infelizmente, essa hipótese não é testada no presente estudo, devendo ser investigada em estudos futuros sobre o tema.

Quanto ao movimento rural-urbano decorrente de secas (Delazeri; Cunha, 2015), a migração da população rural para as áreas urbanas poderia agravar as condições socioeconômicas em virtude da carência de infraestrutura urbana (Souza et al., 2013, Confalonieri et al., 2007). Contudo, a Tabela 1 mostra aumento da taxa de urbanização dos municípios cearenses acompanhado por melhorias nas condições socioeconômicas e de acesso ao abastecimento de água e coleta de esgoto. Ademais, os resultados das Tabelas 2, 3 e 5 são robustos à inclusão de diversas variáveis controle que, de forma direta ou indireta, estão associadas à migração seletiva. Logo, a migração parece não ser um potencial mecanismo de efeito da precipitação pluviométrica sobre a taxa de mortalidade de crianças menores de 5 anos no Ceará.

\section{Conclusões}

O presente estudo investigou a relação entre a flutuação da precipitação pluviométrica sobre a saúde infantil nos municípios cearenses entre 1991 e 2010. Embora o Ceará tenha apresentado substancial evolução do padrão de vida de sua população nesse período, os resultados obtidos mostraram 
que a taxa de mortalidade de crianças menores de 5 anos de vida tende a se deteriorar em municípios com baixa precipitação pluviométrica, especialmente naqueles em que episódios de seca severa ou extrema ocorreram com mais frequência.

Os resultados são robustos à inclusão de condicionantes socioeconômicos e demográficos, os quais capturam diferenças nos níveis de vulnerabilidade dos municípios aos episódios climáticos extremos. A estimação de modelos com medidas alternativas de precipitação, bem como a estimação com variável "placebo" e com variável dependente defasada, fornece maiores evidências de robustez dos resultados do estudo.

Explorando os mecanismos de efeito, observou-se que a disponibilidade de alimentos não se apresenta como mediadora do impacto da precipitação pluviométrica do município sobre a TMC. Por outro lado, observa-se que a proporção de óbitos de crianças por doenças infecciosas se eleva em períodos de escassez de chuva, corroborando Rocha e Soares (2015). Muito provavelmente, o aumento do consumo de água de má qualidade (ou sem tratamento adequado) em períodos de escassez severa de chuvas seja o fator capaz de explicar o aumento dos óbitos de crianças por doenças infecciosas. Dessa forma, as políticas públicas devem garantir não somente o acesso ao abastecimento de água, como também a sua qualidade para o consumo humano.

As evidências encontradas no estudo corroboram a literatura recente que tem mostrado os impactos dos eventos climáticos extremos sobre a saúde infantil no Brasil (Skoufias; Vinhas, 2012; Pereda et al., 2014; Rocha; Soares, 2015). No entanto, o estudo possui limitações, especialmente no que tange à investigação do mecanismo de efeito relacionado à migração seletiva causada potencialmente por mudanças climáticas (Confalonieri et al., 2007; Barbieri et al., 2010; Delazeri; Cunha, 2015). Por outro lado, os resultados encontrados são relevantes, uma vez que os mesmos sugerem que as mudanças climáticas em curso poderão gerar um custo para a sociedade cearense de até 1,5\% do PIB em decorrência dos óbitos de crianças menores de 5 anos de vida até o final do século XXI.

\section{Referências}

ABRAMOWITZ, M.; STEGUN, I. A. Handbook of Mathematical Function, Dover, p. 1.046, 1965. 
ALMOND, D.; CURRIE, J. Human Capital Development Before Age Five. Handbook of Labor Economics, v. 4b, p. 1.315-1.486, 2011.

ALVES, J.; CAVENAGHI, S. Tendências demográficas dos domicílios e das famílias no Brasil. Aparte: Inclusão Social em Debate, 2012. Disponível em: <http://www.ie.ufrj.br/aparte/ pdfs/tendencias_e_de_familias_24ago12.pdf>. Acesso em: 17 maio 2017.

ALVES, D.; BELLUZZO, W. Infant Mortality and Child Health in Brazil, Economics and Human Biology, v. 2, p. 391-410, 2004.

ANDALÓN, M. et al. Weather Shocks and Health at Birth in Colombia. World Development, v. 82, p. 69-82, 2016.

ANGRIST, J. D.; PISCHKE, J. S. Mostly Harmless Econometrics. Princeton: Princeton University Press, 2009.

ASSUNÇÃO, J.; CHEIN, F. Climate Change and Agriculture Productivity in Brazil: Future Perspectives. Environmental and Development Economics, v. 21, n. 5, p. 1-22, 2016.

BARRECA, A. et al. Maybe Next Month? Temperature Shock, Climate Change, and Dynamic Adjustment in Birth Rates. NBER Working Papers, n. 21681, 2015. Disponível em: <http:// www.nber.org/papers/w21681>. Acesso em: 10 jan. 2017.

BARBIERI, A. F. et al. Climate Change and Population Migration in Brazil's Northeast: Scenarios for 2025-2050. Population and Environment, v. 31, p. 344-370, 2010.

BAUER, J. M.; MBURU, S. Effects of Drought on Child Health in Marsabit District, Northern Kenya. Economics and Human Biology, v. 24, p. 74-79, 2017.

BLAIN, G. C.; KAYANO, M. T. 118 anos de dados mensais do índice padronizado de precipitação: série meteorológica de Campinas, Estado de São Paulo. Revista Brasileira de Meteorologia, v. 26, n. 1, p. 137-148, 2011.

CONFALONIERI, U. et al. Human Health. In: PARRY, M. L. et al. (Ed.). Climate Change 2007: Impacts, Adaptation and Vulnerability. Contribution of Working Group II to the Fourth Assessment Report of the Intergovernmental Panel on Climate Change. Cambridge, UK: Cambridge University Press, 2007. pp. 391-431.

CONFALONIERI, U.; RODRIGUEZ, M. Public Health Vulnerability to Climate Change in Brazil. Climate Research, v. 40, p. 175-186, 2009.

CORBI, R. et al. Avaliação econômica de ganhos sociais na área da saúde - estimativas do valor de uma vida estatística para o Brasil. Unpublished manuscript, 2006.

COSTELLO, A. et al. Managing the Health Effects of Climate Change. The Lancet, v. 373, 2009.

CUTLER, D. et al. The Determinants of Mortality. Journal of Economic Perspectives, v. 20, n. 3, p. 97-120, 2006.

DESCHÊNES, O. et al. Climate Change and Birth Weight. American Economic Review: Papers \& Proceedings, v. 99, n. 22, p. 211-217, 2009.

DESCHÊNES, O.; MORETTI, E. Extreme Weather Events, Mortality and Migration. The Review of Economics and Statistics, v. 91, n. 4, p. 659-681, 2009.

DELAZERI, L.M.; CUNHA, D. A. Mudanças climáticas e migração rural-urbana no semiárido brasileiro. In: $43^{\circ}$ ENCONTRO NACIONAL DE ECONOMIA DA ANPEC. Anais... 
Disponível em: <http://www.anpec.org.br/novosite/br/encontro-2015. Acesso em: 30 jan. 2017.

FISCH, $\mathrm{H}$ et al. The Relationship of Long-Term Global Temperature Change and Human Fertility. Medical Hypotheses, v. 61, n. 1, p. 21-28, 2003.

GAMPER-RABINDRAN, S. et al. The Impact of Piped Water Provision on Infant Mortality in Brazil: A Quantile Panel Data Approach. Journal of Economic Development, v. 92, p. 188-200, 2010.

GROPPO, V.; KRAEHNERT, K. Extreme Weather Events and Child Height: Evidence from Mongolia. World Development, v. 86, p. 59-78, 2016.

HAYES, M. J. et al. Monitoring the 1996 Drought Using the Standardized Precipitation Index. Bulletin of the American Meteorological Society, v. 80, n. 3, p. 429-438, 1999.

HODDINOTT, J.; KINSEY, B. Child Growth in the Time of Drought. Bulletin of Economics and Statistics, Oxford, v. 63, n. 4, p. 409-436, 2001.

IRFF, G. et al. Análise dos determinantes socioeconômicos da taxa de mortalidade infantil (TMI) no Ceará. Instituto de Pesquisa e Estratégia Econômica do Ceará. Texto para Discussão, n. 48, 2008. Disponível em: <http://www.ipece.ce.gov.br/index.php/textos-para-discussao >. Acesso em: 15 jan. 2017.

IPCC. Managing the Risks of Extreme Events and Disasters to Advance Climate Change Adaptation. A Special Report of Working Groups I and II of the Intergovernmental Panel On Climate Change [Field, C. B., V. Barros, T. F. Stocker, D. Qin, D. J. Dokken, K. L. Ebi, M. D. Mastrandrea, K. J. Mach, G.-K. Plattner, S. K. Allen, M. Tignor, and P. M. Midgley (Ed.)]. Cambridge, UK; New York, NY, USA, Cambridge University Press, 2012. 582 pp.

LINDOSO, D. P. et al. Integrated Assessment of Smallholder Farming's Vulnerability to Drought in The Brazilian Semi-Arid: A Case Study in Ceará. Climate Change, v. 127, n. 1, p. 93-105, 2014.

MCKEE, T. B. et al. The Relationship of Drought Frequency and Duration to Times Scale. In: CONFERENCE ON APPLIED CLIMATOLOGY, 8, 1993, Boston. American Meteorological Society, Boston: PREPRINTS, p. 179-184, 1993. Anais...

MIRO, V. H. et al. Fatores determinantes para a queda da desigualdade de renda no Ceará na última década. IPECE. Texto para Discussão, n. 92, 2011. Disponível em: <https:// www.ipece.ce.gov.br/wp-content/uploads/sites/45/2014/02/TD_92.pdf >. Acesso em: 25 jan. 2017.

OLIVEIRA, V. H. de; QUINTANA-DOMEQUE, C. Early-Life Environment and Adult Stature in Brazil: An Analysis for Cohorts Born Between 1950 e 1980. Economics \& Human Biology, v. 15, p. 67-80, 2014.

PEREDA, P. C. et al. Climate Change Impacts on Birth Outcomes in Brazil. IDB Working Paper Series, n. 495, 2014. Disponível em: <http://publications.iadb.org/handle/11319/6451>. Acesso em: 21 jul. 2015.

PBMC. Sumário Executivo do Volume 1 - Base Científica das Mudanças Climáticas. Contribuição do Grupo de Trabalho 1. $1^{\circ}$ Relatório de Avaliação Nacional do Painel Brasileiro de Mudanças Climáticas. Volume Especial para a Rio+20. PBMC, Rio de Janeiro, Brasil, 2012, $34 \mathrm{pp}$. 
PHALKEY, R. et al. Systematic Review of Current Efforts to Quantify the Impacts of Climate Change on Undernutrition. PNAS, v. 112, n. 33, E4522-E4529, 2015.

PNUD. Atlas do Desenvolvimento Humano no Brasil. Brasília: PNUD/ONU, 2013. Disponível em: <http://www.atlasbrasil.org.br/2013/>. Acesso em: 05 ago. 2013.

QUEIROZ, S. N.; BAENINGER, R. Migração de retorno: o caso recente das migrações cearenses. Revista Econômica do Nordeste, v. 44, n. 4, p. 833-850, 2013.

RASELLA, D. et al. Effect of a Conditional Cash Transfer Programme on Childhood Mortality: A Nationwide Analysis of Brazilian Municipalities. The Lancet, v. 386, p. 57-64, 2013.

ROCHA, R.; SOARES, R. Evaluating the Impact of Community-Based Health Interventions: Evidence From Brazil's Family Health Program. Journal of Health Economics, v. 19, p. 126158, 2010.

ROCHA, R.; SOARES, R. Water Scarcity And Birth Outcomes In The Brazilian Semiarid. Journal of Development Economics, v. 112, p. 72-91, 2015.

SOUZA, E. C. et al. Impactos de mudanças climáticas sobre o bem-estar relacionado à saúde no Brasil. Pesquisa e Planejamento Econômico, v. 43, n. 1, p. 49-87, 2013.

SKOUFIAS, E.; VINHA, K. Climate Variability and Child Height in Rural Mexico. Economics and Human Biology, v.10, p. 54-73, 2012.

STANK, C. et al. Health Effects of Droughts: A Systematic Review of The Evidence. PLoS Currents. 2013.

SULIANO, D. et al. A influência do clima no desempenho da economia cearense. IPECE, Texto para Discussão, n. 56, 2009. Disponível em: <https://www.ipece.ce.gov.br/wp-content/ uploads/sites/45/2014/02/TD_56.pdf>. Acesso em: 25 jan. 2017.

UNDP. Linking Climate Change Policies to Human Development: Analysis and Advocacy. United Nations, Human Development Report Office, 2009. Disponivel em: <http://hdr.undp. org/en/content/linking-climate-change-policies-human-development-analysis-and-advocacy>. Acesso em: 21 jul. 2015.

WILLMOTT, C. J.; MATSUURA, K. Terrestrial Precipitation: 1900-2014 Gridded Monthly Time Series (version 4.01). University of Delaware, United States of America, 2014a. Disponível em: <http://climate.geog.udel.edu/ climate/html_pages/download.html>. Acesso em: 30 out. 2016.

WILLMOTT, C. J.; MATSUURA, K. Terrestrial Air Temperature: 1900-2014 Gridded Monthly Time Series (version 4.01). University of Delaware, United States of America, 2014b. Disponível em: <http://climate.geog.udel.edu/ climate/html_pages/download.html>. Acesso em: 30 out. 2016.

\section{Sobre os autores}

Victor Hugo de Oliveira - victor.hugo@ipece.ce.gov.br

Instituto de Pesquisa e Estratégia Econômica do Ceará, Fortaleza, Ceará, Brasil.

ORCID: https://orcid.org/0000-0002-4737-7062.

Cleyber Nascimento de Medeiros - cleyber.medeiros@ipece.ce.gov.br

Instituto de Pesquisa e Estratégia Econômica do Ceará, Fortaleza, Ceará, Brasil.

ORCID: https://orcid.org/0000-0002-6626-3415. 
Silva \& Medeiros

\section{Sobre $\mathrm{o}$ artigo}

Recebido em 20 de abril de 2016. Aprovado em 30 de julho de 2017. 


\section{APÊNDICE}

\section{Índice de Precipitação Padronizado}

O Índice de Precipitação Padronizado (IPP) proposto por McKee et al. (1993) baseia-se na estimação da probabilidade de chuvas de determinada localidade por meio da distribuição $\operatorname{Gama}(\alpha, \beta)$. Os parâmetros, $\alpha$ e $\beta$, são estimados via Máxima Verossimilhança de tal forma que:

$$
\hat{\alpha}=\frac{1}{4 A}\left(1+\sqrt{1+\frac{4 A}{3}}\right) \quad \hat{\beta}=\frac{\bar{P}}{\hat{\alpha}} \quad A=\ln \left(\bar{P}_{t}\right)-\frac{\sum \ln \left(\bar{P}_{t}\right)}{N}
$$

onde $P$ é a precipitação mensal do município, e $N$ é o número de meses. No período de 1940 a 2014, a precipitação média em cada um dos 184 municípios cearenses foi obtida para 900 meses. Todavia, a distribuição Gama não é definida para uma variável aleatória com valores nulos, ou seja, $P=0$. Logo, sua distribuição cumulativa é modificada para incluir tais eventos, ou seja,

$$
H\left(P_{t}\right)=q+(1-q) G\left(P_{t}\right) \quad q=\frac{M}{N}
$$

onde $M$ é o número de meses entre 1940 e 2014 com precipitação nula no município.

Finalmente, a distribuição acumulada $H\left(P_{t}\right)$ é transformada em uma distribuição normal padronizada usando o seguinte procedimento (Abramowitz; Stegun, 1965):

$$
\begin{gathered}
I P P= \begin{cases}-\left(a-\frac{c_{0}+c_{1} a+c_{2} a^{2}}{1+d_{1} a+d_{2} a^{2}+c_{3} a^{3}}\right), & \text { se } 0<H\left(P_{t}\right) \leq 0,5 \\
+\left(a-\frac{c_{0}+c_{1} a+c_{2} a^{2}}{1+d_{1} a+d_{2} a^{2}+c_{3} a^{3}}\right), & \text { se } 0,5<H\left(P_{t}\right) \leq 1\end{cases} \\
a= \begin{cases}\sqrt{\frac{1}{H\left(P_{t}\right)^{2}},} \quad \text { se } 0<H\left(P_{t}\right) \leq 0,5 \\
\sqrt{\frac{1}{\left(1-H\left(P_{t}\right)\right)^{2}}} \quad \text { se } 0,5<H\left(P_{t}\right) \leq 1\end{cases}
\end{gathered}
$$


onde $c_{0}=2,515517, c_{1}=0,802853, c_{2}=0,010328, d_{1}=1,432788, d_{1}=0,189269$ e $d_{3}=0,001308$. O Quadro A1 apresenta a classificação do regime de chuvas com base no IPP, convencionada na literatura internacional.

Quadro A1 Classificação do regime de chuvas com base no Índice de Precipitação Pluviométrica

\begin{tabular}{l|r}
\hline Intervalos & Categorias \\
\hline$I P P \geq 2,0$ & Extremamente úmido \\
\hline $1,5 \leq I P P<2,0$ & Severamente úmido \\
\hline $1,0 \leq I P P<1,5$ & Moderadamente úmido \\
\hline $0,0<I P P<1,0$ & Umidade incipiente \\
\hline $0,0 \leq I P P<-1,0$ & Seca incipiente \\
\hline$-1,0 \leq I P P<-1,5$ & Moderadamente seco \\
\hline$-1,5 \leq I P P<-2,0$ & Severamente seco \\
\hline$I P P \leq-2,0$ & Extremamente seco \\
\hline
\end{tabular}

Fonte: Blain; Kayano (2011).

Hayes et al. (1999) sugerem que $68 \%$ dos valores do IPP estejam no intervalo entre -1 e 1 , e $95 \%$ entre -2 e 2 , considerando uma longa série de precipitação. Por possuir média e desvio padrão fixos, o IPP pode ser comparado entre diferentes regiões e localidades. 